\title{
PENGELOMPOKAN KABUPATEN/KOTA DI JAWA TIMUR BERDASARKAN INDIKATOR INDEKS PEMBANGUNAN MANUSIA MENGGUNAKAN METODE SOM
}

\author{
(District / City Grouping In Jawa Timur Based On Human Development Index \\ Indicators Using The Som Method)
}

\author{
Ahmad Mushonnif \\ Prodi. Teknik Informatika, Fakultas Teknik, Universitas Muhammadiyah Surabaya \\ Jl. Sutorejo No. 59 Surabaya, Jawa Timur, Indonesia, 60113
}

Email: mushonnif3@gmail.com

\begin{abstract}
Human Development Index (HDI) explains how residents can access development results in obtaining income, health, education, and so forth. HDI is based on indicators of health, education and decent living standards. In 2010 to 2014, the achievement of HDI of East Java province rose by 2.78 points from 65.36 into 68.14 . But behind the development achievements of HDI, East Java province was ranked 21 out of 34 provinces in Indonesia. Three indicators have relevance in forming HDI value formation. In East Java province high and low HDI regencies or cities are shown only through a composite index, but it was not indicated where the dominant indicator of high or low rank on the HDI. Clustering regencies or cities based on indicators IPM needs to be done to ascertain the achievement of each indicator. Clustering method that can be used are Self-Organizing Maps (SOM). Based on the results of research and discussion conducted, for health indicator, 6 regency/city in the group of low, 12 regency/city in the group of medium, 16 regency/city in the group of high, and 4 regency/city in the group of very high. For educational indicator, 2 regency/city in the group of low, 15 regency/city in the group of medium, 13 regency/city in the group of high, and 8 regency/city in the group of very high. For educational indicator, 2 regency/city in the group of low, 15 regency/city in the group of medium, $13 \mathrm{regency} / \mathrm{city}$ in the group of high, and 8 regency/city in the group of very high. For decent living standard indicators, 2 regency/city in the group of low, 15 regency/city in the group of medium, 13 regency/city in the group of high, and 8 regency/city in the group of very high. For educational indicator, 4 regency/city in the group of low, 21 regency/city in the group of medium, 10 regency/city in the group of high, and 3 regency/city in the group of very high.
\end{abstract}

Key word : Human Development Index, Clustering, Self-Organizing Maps.

\section{PENDAHULUAN}

Indeks Pembangunan Manusia (IPM) pertama kali diperkenalkan oleh United Nation Development Program (UNDP) pada tahun 1990. IPM menjelaskan bagaimana penduduk dapat mengakses hasil pembangunan dalam memperoleh pendapatan, kesehatan, pendidikan, dan sebagainya. IPM didasarkan pada indikator Kesehatan,
Pendidikan, dan Standar Hidup Layak. Provinsi Jawa Timur merupakan salah satu provinsi di Indonesia yang memiliki perkembangan yang cukup baik dalam pembangunan kependudukan. Hal ini ditunjukkan bahwa selama beberapa tahun terakhir pencapaian angka Indeks Pembangunan Manusia (IPM) Jawa Timur terus meningkat. Pada tahun 2010 sampai 2014, pencapaian angka IPM Provinsi Jawa Timur mengalami kenaikan sebesar 2,78 poin dari 65,36 menjadi 68,14 (Badan Pusat Statistik, 2016). Namun dibalik perkembangan capaian IPM tersebut, Provinsi Jawa Timur berada diurutan 21 dari 34 provinsi yang ada di Indonesia (Badan Pusat Statistik, 2016).

Pencapaian IPM Provinsi Jawa Timur tidak terlepas dari dukungan sarana dan prasarana yang ada di setiap kabupaten atau kota. Sebagai contoh, jumlah puskesmas atau rumah sakit disuatu kabupaten atau kota berkorelasi terhadap indikator kesehatan. Begitu pula dengan indikator-indikator lainnya, ada keterkaitan antara indikator satu dengan indikator lainnya yang mempengaruhi IPM di tingkat Provinsi. Di Provinsi Jawa Timur tinggi rendahnya IPM kabupaten atau kota hanya ditunjukkan melalui indeks komposit, tetapi tidak ditunjukkan indikator mana yang dominan terhadap tinggi atau rendahnya peringkat IPM. Padahal, nilai dari tiap-tiap indikator pembentuk IPM perlu dilihat agar dapat diketahui pencapaian dari tiap-tiap indikator.

Selain menggunakan IPM yang hanya berupa indeks komposit sebagai indikator Provinsi Jawa Timur secara umum, penting juga untuk melakukan pengelompokan wilayah kabupaten atau kota berdasarkan indikator IPM. Pengelompokan wilayah bertujuan untuk membagi wilayah-wilayah ke dalam beberapa kelompok dengan karakteristik yang memiliki keserupaan tinggi di dalam setiap kelompok dan berbeda antar kelompok. Pengelompokan tersebut dapat membantu Pemerintah Provinsi Jawa Timur sebagai bahan perencanaan dan kebijakan pemerintah untuk meningkatkan angka pembangunan manusia di Provinsi Jawa Timur. 
Ada beberapa algoritma pengelompokan yang dapat digunakan, salah satu diantaranya adalah Self Organizing Maps (SOM). Marina dan Kartika (2015) telah melakukan penelitian tentang pengelompokan yaitu pengelompokan kabupaten atau kota di Jawa Timur berdasarkan Indikator Kesehatan Masyarakat menggunakan Metode Kohonen SOM dan K-Means dengan tujuan supaya Tim Pembina Kota Sehat Provinsi Jawa Timur dapat melakukan pembinaan dan monitoring terhadap kelompok kabupaten atau kota yang terbentuk berdasarkan kemiripan karakteristik kondisi kesehatan masyarakat. Dari penelitian dengan menggunakan metode SOM tersebut didapatkan nilai icdrate sebesar 0,962 dengan hasil pada setiap kelompok yang terbentuk memiliki perbedaan.

\section{II.TINJAUAN PUSTAKA}

\section{A. Indeks Pembangunan Manusia}

Pengukuran pembangunan manusia pertama kali diperkenalkan oleh United Nations Development Programs (UNDP) pada tahun 1990. UNDP memperkenalkan sebuah gagasan baru dalam pengukuran pembangunan manusia yang disebut sebagai Indeks Pembangunan Manusia (IPM). Sejak saat itu, IPM dipublikasikan secara berkala dalam laporan tahunan Human Development Report (HDR). IPM menjelaskan bagaimana penduduk dapat mengakses hasil pembangunan dalam memperoleh pendapatan, kesehatan, pendidikan, dan sebagainya (BPS, 2015).

Menurut UNDP, Indeks Pembangunan Manusia (IPM) mengukur capaian pembangunan manusia berbasis sejumlah komponen dasar kualitas hidup. Sebagai ukuran kualitas hidup, IPM dibangun melalui pendekatan tiga dimensi dasar. Dimensi tersebut mencakup:

1) kesehatan atau umur panjang dan hidup sehat ( $a$ long and healthy life);

2) pengetahuan (knowledge); dan

3) standar hidup layak (decent standard of living).

Ketiga dimensi tersebut memiliki pengertian sangat luas karena terkait banyak faktor. Pada laporan pertamanya, UNDP mengukur dimensi kesehatan dengan menggunakan angka harapan hidup waktu lahir. Selanjutnya untuk mengukur dimensi pengetahuan digunakan angka melek huruf. Adapun untuk mengukur dimensi standar hidup layak digunakan indikator Produk Domestik Bruto (PDB) per kapita (BPS, 2015).

\section{B. Clustering}

Pada dasarnya clustering atau pengelompokan terhadap data adalah suatu proses melakukan pemisahan atau segmentasi data ke dalam sejumlah kelompok (cluster) menurut karakteristik tertentu yang diinginkan, dalam pekerjaan pengelompokan, label dari setiap data belum diketahui, dan dengan pengelompokan diharapkan dapat diketahui kelompok data untuk kemudian diberi label sesuai keinginan. Tujuannya adalah agar objek-objek yang bergabung dalam sebuah kelompok merupakan objek-objek yang mirip (atau berhubungan) satu sama lain dan berbeda (atau tidak berhubungan) dengan objek dalam kelompok yang lain. Lebih besar kemiripannya (homogenitas) dalam kelompok dan lebih besar perbedaannya diantara kelompok yang lain (Prasetyo, E. 2012).

\section{Self Organizing Maps}

Self Organizing Maps (SOM) pertama kali diperkenalkan oleh Kohonen (Kohonen, 1989) dengan teknik pelatihan Artificial Neural Network (ANN) atau Jaringan Syaraf Tiruan (JST) yang menggunakan basis winner takes all, dimana hanya neuron yang menjadi pemenang yang akan diperbarui bobotnya. Meskipun menggunakan basis ANN, SOM tidak menggunakan nilai target kelas, tidak ada kelas yang ditetapkan untuk setiap data. Karakteristik seperti inilah yang kemudian membuat SOM dapat digunakan untuk keperluan pengelompokan (berbasis ANN) (Prasetyo, E. 2012).

\section{C.1. Algoritma Pengelompokan SOM}

Berikut ini adalah langkah-langkah yang perlu dilakukan dalam menerapkan metode SOM dalam pengolahan data (Prasetyo, E. 2012).

1) Inisialisasi bobot wij. Tentukan parameter topologi ketetanggaan. Tentukan parameter laju pembelajaran dan fungsi pembelajaran. Tentukan jumlah maksimal iterasi pelatihan.

2) Selama jumlah maksimal iterasi belum tercapai, lakukan langkah 3-7.

3) Untuk setiap data masukan X, lakukan langkah 4-6.

4) Untuk setiap neuron j, hitung menggunakan persamaan

$D_{j}=\sum_{i}\left(w_{i j}-x_{i}\right)^{2}, i=1, \ldots, N$ dengan $\mathrm{N}$ adalah dimensi data $(\mathrm{N})$

5) Cari indeks dari sejumlah neuron, yaitu $D_{j}$, yang mempunyai nilai terkecil.

6) Untuk neuron $\mathrm{j}$ dan semua neuron yang menjadi tetangga $\mathbf{J}$ (yang sudah didefinisikan) dalam radius $\mathrm{R}$ dilakukan pembaruan bobot dengan persamaan $w_{i j}($ baru $)=w_{i j}($ lama $)+\eta\left(x_{i}-w_{i j}(\right.$ lama $\left.)\right)$

7) Perbarui nilai laju pembelajaran Pada algoritma di atas, parameter jarak untuk perbedaan atau kemiripan yang digunakan adalah Euclidean kuadrat (square euclidean). Hal ini dimaksudkan untuk mengurangi waktu komputasi dan menyederhanakan kinerja algoritma, tetapi harus dibayar dengan penggunaan memori yang lebih besar untuk alokasi nilai jarak yang biasanya besar. Nilai laju pembelajaran ( $\eta$ ) yang digunakan menggunakan jangkauan nilai 0 sampai 1. Tetapi nilai ini akan terus diturunkan setiap kali ada kenaikan iterasi dengan sebuah fungsi pembelajaran (learning function); penurunan geometrik akan memberikan hasil yang sama. Inisialisasi bobot awal bisa menggunakan nilai acak dengan jangkauan -0.5 sampai +0.5 , atau menggunakan nilai acak dengan jangkauan nilai seperti pada data masukan.

Keterangan : 
$\mathrm{X}$ : adalah matriks $\mathrm{MxN}, \mathrm{M}$ menyatakan jumlah data dan $\mathrm{N}$ menyatakan jumlah fitur

C : menyatakan jumlah kelompok (neuron pemroses)

\section{III.METODE PENELITIAN}

\section{A. Analisis Sistem}

Indeks Pembangunan Manusia (IPM) merupakan indikator penting untuk mengukur keberhasilan dalam upaya membangun kualitas hidup manusia. IPM terbentuk dari tiga indikator, yakni indikator kesehatan, indikator pendidikan, dan indikator standar hidup layak. Ketiga indikator pembentuk IPM tersebut tersusun dari beberapa indikator lain. Dalam perhitungan IPM metode baru, indikator kesehatan diukur melalui indikator Angka Harapan Hidup saat lahir dengan jenis data yang digunakan adalah Anak Lahir Hidup dan Anak Masih Hidup. Selanjutnya indikator pendidikan diukur melalui angka rata-rata lama sekolah dan harapan lama sekolah. Adapun indikator standar hidup layak menggunakan ratarata pengeluaran per kapita riil yang disesuaikan dengan paritas daya beli berdasarkan komoditas bahan pokok. (BPS, 2015).

Di Provinsi Jawa Timur tinggi rendahnya IPM kabupaten atau kota ditunjukkan melalui indeks komposit, tetapi tidak ditunjukkan tiap-tiap indikator pembentuk IPM. Padahal, nilai dari tiap-tiap indikator pembentuk IPM perlu dilihat agar dapat diketahui pencapaian dari tiap-tiap indikator. Pengelompokan wilayah bertujuan untuk membagi wilayah-wilayah ke dalam beberapa kelompok dengan karakteristik yang memiliki keserupaan tinggi di dalam setiap kelompok dan berbeda antar kelompok. Pengelompokan tersebut dapat membantu Pemerintah Provinsi Jawa Timur sebagai bahan perencanaan dan kebijakan pemerintah untuk meningkatkan angka pembangunan manusia di Provinsi Jawa Timur.

Selain menggunakan IPM yang hanya berupa indeks komposit sebagai indikator Provinsi Jawa Timur secara umum, penting juga untuk melakukan pengelompokan wilayah kabupaten atau kota berdasarkan indikator pembentuk IPM. Oleh karena itu, dibutuhkan pengelompokan kabupaten atau kota di Jawa Timur berdasarkan masing-masing indikator pembentuk IPM ke dalam kategori sangat tinggi, tinggi, sedang dan rendah.

\section{B. Hasil Analisis}

Sistem pengelompokan yang dibangun menggunakan metode SOM. Sistem ini menghasilkan keluaran berupa kelompok-kelompok kabupaten atau kota yang akan tergolong ke dalam kategori rendah, sedang, tinggi atau sangat tinggi.

Terdapat beberapa parameter yang dibutuhkan untuk melakukan pengelompokan kabupaten atau kota di Jawa Timur berdasarkan indikator pembentuk IPM. Parameter tersebut dapat dilihat pada tabel 1 .
TABLE III. PARAMETER INDIKATOR PEMBENTUK IPM

\begin{tabular}{|c|l|l|}
\hline No & \multicolumn{1}{|c|}{ Indikator } & \multicolumn{1}{c|}{ Parameter } \\
\hline \multirow{2}{*}{1} & \multirow{3}{*}{ Kesehatan } & Angka Harapan Hidup (AHH) \\
\cline { 3 - 3 } & & Angka Lahir Hidup (ALH) \\
\cline { 3 - 4 } 2 & \multirow{2}{*}{ Pendidikan } & Angka Masih Hidup (AMH) \\
\cline { 3 - 4 } 3 & \multirow{2}{*}{ Standar Hidup Layak } & Rarapan Lama Sekolah (HLS) \\
\cline { 3 - 4 } & & Pengeluaran Pama Sekolah (RLS) \\
\hline
\end{tabular}

Alur sistem pengelompokan kabupaten atau kota di Jawa Timur berdasarkan indikator pembentuk IPM dapat dilihat pada gambar 1 .
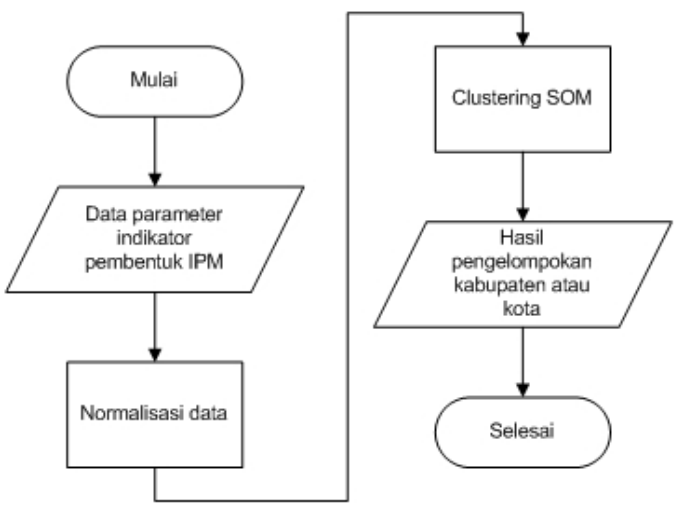

Gambar 1 Diagram Alur Sistem

Penjelasan gambar 1 :

1) Memasukkan data parameter sesuai dengan indikator pembentuk IPM yang akan diolah oleh sistem

2) Normalisasi data sebelum dilakukan proses perhitungan dengan metode SOM

3) Proses perhitungan dengan metode SOM menggunakan data parameter hasil dari normalisasi

4) Selanjutnya sistem menampilkan hasil pengelompolan dengan Metode SOM

\section{Perancangan Sistem}

\section{C.1. Diagram Konteks}

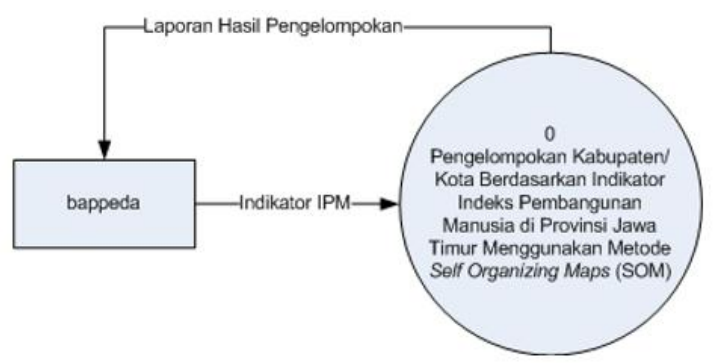

Gambar 2 Diagram Konteks

Diagram konteks pada gambar 2 menggambarkan input dan output antara sistem dengan kesatuan luar (external entitiy). Keterangan gambar 2, Bappeda yaitu pihak yang memasukkan indikator IPM serta dapat melihat laporan hasil pengelompokan kabupaten atau kota untuk masingmasing indikator. 


\section{C.2. Diagram Hirarkhi Proses}

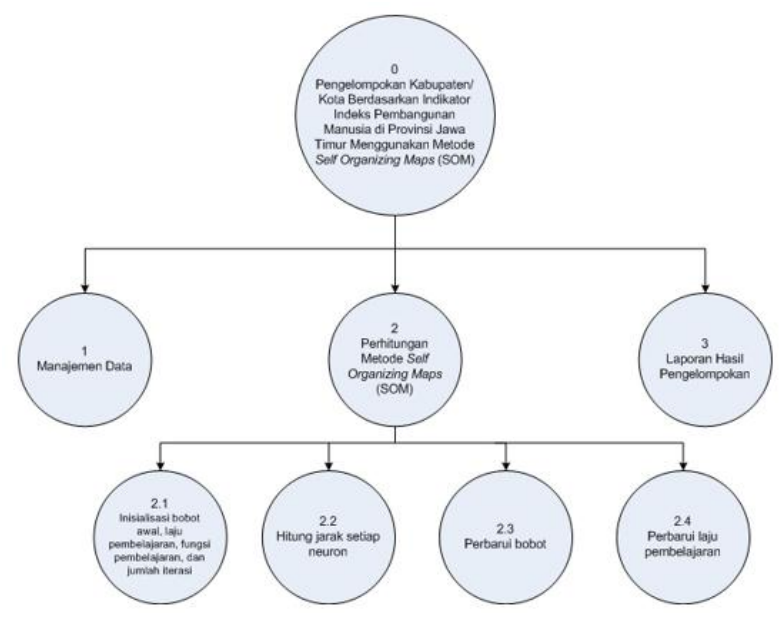

Gambar 3 Diagram Hirarkhi Proses

Dari gambar 3 dapat dilihat secara keseluruhan proses yang akan dilakukan pada sistem pengelompokan kabupaten atau kota berdasarkan indikator Indeks Pembangunan Manusia menggunakan metode Self Organizing Maps (SOM). Penjelasan dari gambar 3 sebagai berikut:

1) Top level: Pengelompokan kabupaten atau kota berdasarkan indikator Indeks Pembangunan Manusia (IPM) di Jawa Timur menggunakan metode Self Organizing Maps (SOM).

2) Level 1 proses: Berisi proses dalam sistem meliputi manajemen data, perhitungan metode SOM, dan laporan hasil pengelompokan.

3) Level 2: Merupakan proses perhitungan metode SOM yang memuat perhitungan atau tahapantahapan dalam menggunakan algoritma Self Organizing Maps (SOM).

\section{C.3. DFD Level 1}

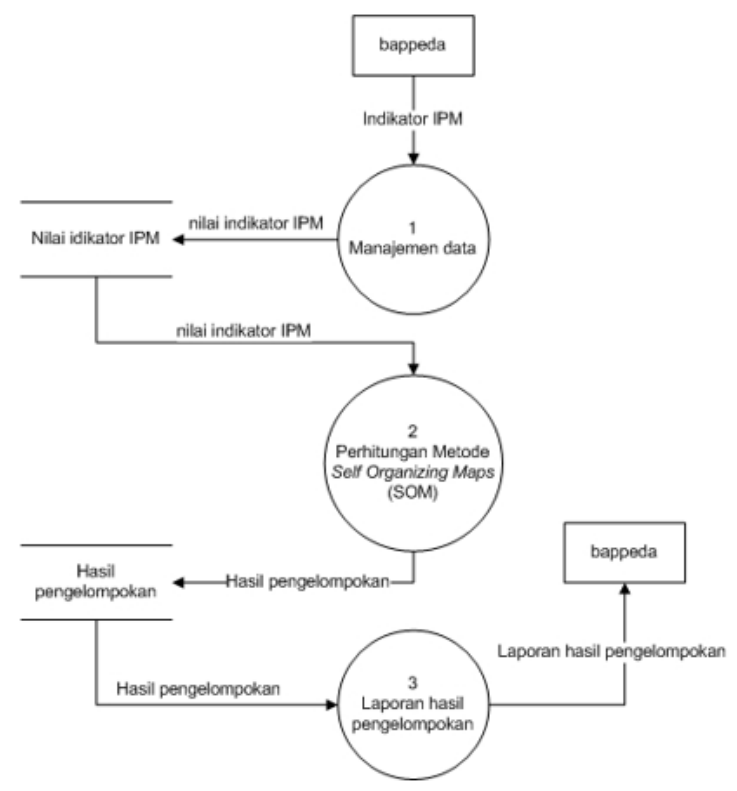

Gambar 4 Data Flow Diagram Level 1

Adapun rincian DFD level 1 seperti yang diperlihatkan gambar 4 yaitu:

1) Proses 1 manajemen data, merupakan proses memasukkan data indikator IPM serta pemilihan data yang termasuk ke dalam kategori indikator pendidikan, kesehatan atau standar hidup layak sebelum data siap untuk diproses.

2) Proses 2 perhitungan self organizing map yaitu proses perhitungan menggunakan metode Self Organizing Map sesuai algoritma.

3) Proses 3 laporan hasil cluster yaitu proses pembuatan laporan dari proses clustering. User memperoleh laporan hasil pengelompokan kabupaten atau kota dari masing-masing indikator.

\section{C.4. DFD Level 2}

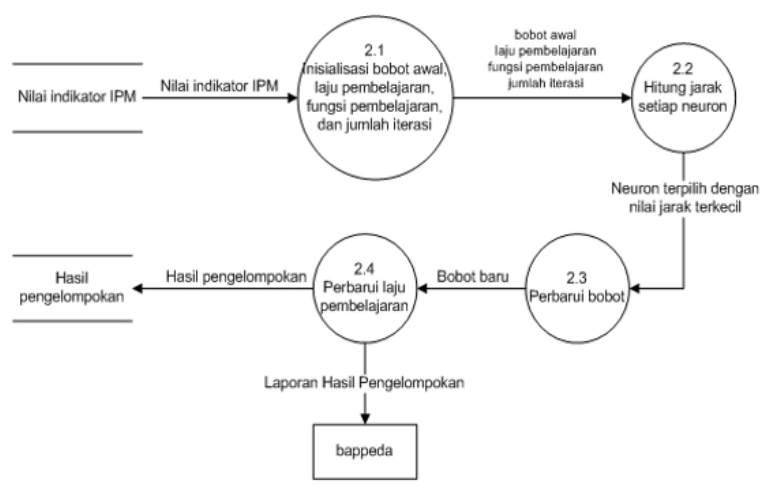

Gambar 5 Data Flow Diagram Level

Adapun rincian DFD level 2 seperti yang diperlihatkan pada gambar 5 yaitu :

1) Proses 2.1 inisialisasi bobot yang dipilih secara acak dari rentan data, menentukan parameter laju pembelajaran, menentukan jumlah iterasi. 
2) Proses 2.2 menghitung jarak tiap neuron yaitu proses perhitungan dengan memilih jarak neuron terkecil.

3) Proses 2.3 perbarui bobot yaitu memperbarui bobot dari neuron terpilih dengan cara bobot lama ditambah laju pembelajaran dikali data dikurangi bobot lama untuk setiap data yang di hitung.

Proses 2.4 perbarui laju pembelajaran yaitu proses untuk mengitung bobot pada iterasi kedua caranya nilai laju pembelajaran dikali dengan fungsi pembelajaran. Proses pengelompokan yang telah dilakukan nantinya disimpan dalam tabel hasil pengelompokan.

\section{HASIL DAN PEMBAHASAN}

Pengujian sistem dilakukan dengan beberapa skenario. Skenario pengujian pertama dilakukan untuk menguji tingkat akurasi sistem yang dibangun. Pengujian dilakukan sebanyak 5 kali dengan cara membandingkan hasil pengelompokan SOM yang menggunakan 7 macam atribut meliputi Angka Harapan Hidup, Angka Lahir Hidup, Angka Masih Hidup, Rata-rata Lama Sekolah, Harapan Lama Sekolah, Paritas Daya Beli, dan Pengeluaran Perkapita dengan pengelompokan IPM standar Bappeda. Pengujian dilakukan sebanyak 5 kali dengan jumlah kelompok sebanyak 4 dan bernilai sama untuk setiap pengujian. Inisialisasi nilai bobot didapatkan secara acak dengan nilai antara 0 sampai 1 dan sama untuk setiap pengujian. Laju pembelajaran dan fungsi pembelajaran mempunyai nilai antara 0 sampai 1 dan berbeda untuk setiap pengujian. Bobot yang digunakan untuk setiap percobaan ini adalah sebagai berikut.

$$
w=\left[\begin{array}{llll}
0.2 & 0.5 & 0.7 & 0.1 \\
0.3 & 0.2 & 0.4 & 0.2 \\
0.5 & 0.2 & 0.2 & 0.4 \\
0.1 & 0.6 & 0.1 & 0.3 \\
0.7 & 0.1 & 0.3 & 0.6 \\
0.2 & 0.4 & 0.2 & 0.5 \\
0.1 & 0.6 & 0.6 & 0.2
\end{array}\right]
$$

Pada percobaan pertama menggunakan parameter jumlah kelompok 4, laju pembelajaran 0,5, fungsi pembelajaran 0,6, dan jumlah iterasi 5. Percobaan pertama memperoleh hasil 16 data mengikuti cluster 1, 8 data mengikuti cluster 2, 3 data mengikuti cluster 3, dan 11 data mengikuti cluster 4. Dari 38 kabupaten/kota diperoleh hasil 23 kabupaten/kota sesuai dengan kelompok IPM standar Bappeda dan 15 kabupaten/kota belum sesuai dengan kelompok IPM standar Bappeda. Hasil pengujian Akurasi percobaan pertama sampai percobaan kelima dapat dilihat pada tabel 2.

TABLE IV. HASIL PENGUJIAN AKURASI

\begin{tabular}{|c|c|c|c|c|c|c|}
\hline \multirow{2}{*}{$\begin{array}{c}\text { Percobaan } \\
\text { ke- }\end{array}$} & \multirow[b]{2}{*}{ Relevan } & \multicolumn{4}{|c|}{ Terbaca } & \multirow[b]{2}{*}{ Akurasi } \\
\hline & & Rendah & Sedang & Tinggi & $\begin{array}{l}\text { Sangat } \\
\text { Tinggi }\end{array}$ & \\
\hline \multirow{4}{*}{1} & Rendah & 1 & 0 & 0 & 0 & \multirow{4}{*}{$60.52 \%$} \\
\hline & Sedang & 10 & 14 & 0 & 0 & \\
\hline & Tinggi & 0 & 2 & 8 & 3 & \\
\hline & Sangat Tinggi & 0 & 0 & 0 & 0 & \\
\hline \multirow{4}{*}{2} & Rendah & 1 & 0 & 0 & 0 & \multirow{4}{*}{$76.31 \%$} \\
\hline & Sedang & 6 & 18 & 0 & 0 & \\
\hline & Tinggi & 0 & 1 & 10 & 2 & \\
\hline & Sangat Tinggi & 0 & 0 & 0 & 0 & \\
\hline \multirow{4}{*}{3} & Rendah & 0 & 1 & 0 & 0 & \multirow{4}{*}{$84.21 \%$} \\
\hline & Sedang & 5 & 19 & 0 & 0 & \\
\hline & Tinggi & 0 & 0 & 13 & 0 & \\
\hline & Sangat Tinggi & 0 & 0 & 0 & 0 & \\
\hline \multirow{4}{*}{4} & Rendah & 1 & 0 & 0 & 0 & \multirow{4}{*}{$73.68 \%$} \\
\hline & Sedang & 5 & 18 & 1 & 0 & \\
\hline & Tinggi & 0 & 4 & 9 & 0 & \\
\hline & Sangat Tinggi & 0 & 0 & 0 & 0 & \\
\hline \multirow{4}{*}{5} & Rendah & 1 & 0 & 0 & 0 & \multirow{4}{*}{$68.42 \%$} \\
\hline & Sedang & 10 & 14 & 0 & 0 & \\
\hline & Tinggi & 0 & 2 & 11 & 0 & \\
\hline & Sangat Tinggi & 0 & 0 & 0 & 0 & \\
\hline
\end{tabular}

Skenario pengujian yang kedua dilakukan untuk menguji sekaligus evaluasi sistem pada 3 indikator yakni indikator kesehatan, indikator pendidikan, dan indikator standar hidup layak. Pengujian dilakukan sebanyak lima kali dengan jumlah kelompok sebanyak 4 dan bernilai sama untuk setiap pengujian. Inisialisasi nilai bobot didapatkan secara acak dengan nilai antara 0 sampai 1 dan sama untuk setiap pengujian. Laju pembelajaran dan fungsi pembelajaran mempunyai nilai antara 0 sampai 1 dan berbeda untuk setiap pengujian. Selanjutnya hasil dari setiap pengujian akan dilakukan evaluasi sistem dengan menggunakan metode Davies Bouldin Index (DBI).

\section{1) Indikator Kesehatan}

Pada indikator kesehatan, jumlah kelompok untuk setiap percobaan adalah 4 dan bobot yang digunakan untuk setiap percobaan ini adalah sebagai berikut.

$$
w=\left[\begin{array}{llll}
0.5 & 0.2 & 0.1 & 0.3 \\
0.1 & 0.1 & 0.5 & 0.4 \\
0.2 & 0.4 & 0.3 & 0.1
\end{array}\right]
$$

Hasil Evaluasi dari percobaan pertama sampai kelima dapat dilihat pada tabel 3 .

TABLE V. Evaluasi Pengujian IndiKator Kesehatan

\begin{tabular}{|c|ccc|c|c|c|c|c|}
\hline $\begin{array}{c}\text { Percobaan } \\
\text { ke - }\end{array}$ & Bobot akhir & $\begin{array}{c}\text { Clst. } \\
\mathbf{1}\end{array}$ & $\begin{array}{c}\text { Clst. } \\
\mathbf{2}\end{array}$ & $\begin{array}{c}\text { Clst. } \\
\mathbf{3}\end{array}$ & $\begin{array}{c}\text { Clst. } \\
\mathbf{4}\end{array}$ & DBI \\
\hline \multirow{2}{*}{1} & {$\left[\begin{array}{llll}0.7792 & 0.1538 & 0.3805 & 0.7428 \\
0.8590 & 0.2438 & 0.3975 & 0.1764 \\
0.8549 & 0.2727 & 0.3943 & 0.1750\end{array}\right]$} & 5 & 4 & 7 & 22 & 0.5022 \\
\hline \multirow{2}{*}{2} & {$\left[\begin{array}{llll}0.7861 & 0.7296 & 0.1836 & 0.6845 \\
0.9092 & 0.0887 & 0.3161 & 0.3811 \\
0.9050 & 0.0879 & 0.3136 & 0.3782\end{array}\right]$} & 4 & 12 & 6 & 16 & 0.2984 \\
\hline 3 & {$\left[\begin{array}{llll}0.7447 & 0.2086 & 0.1408 & 0.7281 \\
0.5880 & 0.1071 & 0.3618 & 0.1373 \\
0.5847 & 0.3847 & 0.3279 & 0.1360\end{array}\right]$} & 13 & 1 & 6 & 18 & 0.9537 \\
\hline \multirow{3}{*}{3} & {$\left[\begin{array}{llll}0.7172 & 0.1590 & 0.4814 & 0.3123 \\
0.2048 & 0.1798 & 0.6500 & 0.3652 \\
0.2043 & 0.3644 & 0.5886 & 0.1310\end{array}\right]$} & 23 & 4 & 8 & 3 & 0.8234 \\
\hline 5 & {$\left[\begin{array}{llll}0.7306 & 0.2394 & 0.1571 & 0.7324 \\
0.5183 & 0.2812 & 0.5571 & 0.1212 \\
0.5152 & 0.2987 & 0.5188 & 0.1200\end{array}\right]$} & 15 & 6 & 2 & 15 & 0.8758 \\
\hline
\end{tabular}

Berdasarkan hasil evaluasi tersebut maka kelompok yang terbentuk adalah hasil dari percobaan kedua karena mempunyai nilai DBI paling rendah. Kelompok kabupaten 
atau kota untuk indikator kesehatan dapat dilihat pada tabel 4.

TABLE VI. HASIL PENGELOMPOKAN INDIKATOR KeSEHATAN

\begin{tabular}{|c|c|c|}
\hline No. & Kabupaten / Kota & Kelompok \\
\hline & Pacitan & SEDANG \\
\hline & Ponorogo & TINGGI \\
\hline 3 & Trenggalek & SEDANG \\
\hline & Tulumgagung & TINGGI \\
\hline 5 & Blitar & TINGGI \\
\hline 6 & Kediri & TINGGI \\
\hline & Malang & SANGAT TINGGI \\
\hline 8 & Lumajang & RENDAH \\
\hline 9 & Jember & SANGAT TINGGI \\
\hline 10 & Banyuwangi & TINGGI \\
\hline 11 & Bondowioso & RENDAH \\
\hline 12 & Situbondo & RENDAH \\
\hline 13 & Probolinggo & RENDAH \\
\hline 14 & Pasuruan & SEDANG \\
\hline 15 & Sidoarjo & SANGAT TINGGI \\
\hline 16 & Mojokerto & TINGGI \\
\hline 17 & Jombang & TINGGI \\
\hline 18 & Nganjulk & TINGGI \\
\hline & 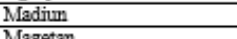 & SEDANG \\
\hline 20 & Magetan & SEDANG \\
\hline 21 & Ngawi & TINGGI \\
\hline & Bojonegoro & IINGGI \\
\hline 23 & Tuban & TINGGI \\
\hline 24 & Lamongan & TINGGI \\
\hline 25 & Gresik & TINGGI \\
\hline 26 & Bangkalan & TINGGI \\
\hline 27 & Sampang & RENDAH \\
\hline 28 & Pamekasan & RENDAH \\
\hline & Sumenep & TINGGI \\
\hline 30 & Kota Kediri & SEDANG \\
\hline 31 & Kota Blitar & SEDANG \\
\hline 32 & Kota Malang & TINGGI \\
\hline 33 & Kota Probolinggo & SEDANG \\
\hline 34 & Kota Paguruan & SEDANG \\
\hline 35 & Kota Mojokerto & SEDANG \\
\hline 36 & Kota Madium & SEDANG \\
\hline 37 & Kota Surabaya & SANGAT TINGGI \\
\hline 38 & Kota Batu & SEDANG \\
\hline
\end{tabular}

2) Indikator Pendidikan

Pada indikator pendidikan, jumlah kelompok untuk setiap percobaan adalah 4 dan bobot yang digunakan untuk setiap percobaan ini adalah sebagai berikut.

$$
w=\left[\begin{array}{llll}
0.3 & 0.1 & 0.2 & 0.5 \\
0.2 & 0.4 & 0.3 & 0.1
\end{array}\right]
$$

Hasil Evaluasi dari percobaan pertama sampai kelima dapat dilihat pada tabel 5 .

TABLE VII. Evaluasi Pengujian Indikator Pendidikan

\begin{tabular}{|c|ccc|c|c|c|c|c|}
\hline $\begin{array}{c}\text { Percobaan } \\
\text { ke - }\end{array}$ & Bobot akhir & $\begin{array}{c}\text { Clst. } \\
\mathbf{1}\end{array}$ & $\begin{array}{c}\text { Clst. } \\
\mathbf{2}\end{array}$ & $\begin{array}{c}\text { Clst. } \\
\mathbf{3}\end{array}$ & $\begin{array}{c}\text { Clst. } \\
\mathbf{4}\end{array}$ & DBI \\
\hline 1 & {$\left[\begin{array}{llll}0.0955 & 0.3535 & 0.6417 & 0.7868 \\
0.1013 & 0.3769 & 0.5168 & 0.8755\end{array}\right]$} & 2 & 15 & 13 & 8 & 0.3141 \\
\hline 2 & {$\left[\begin{array}{llll}0.3486 & 0.0847 & 0.6385 & 0.7867 \\
0.3820 & 0.0996 & 0.5098 & 0.8736\end{array}\right]$} & 15 & 2 & 13 & 8 & 0.3098 \\
\hline 3 & {$\left[\begin{array}{lllll}0.1817 & 0.1913 & 0.4881 & 0.7392 \\
0.1564 & 0.3766 & 0.3961 & 0.7983\end{array}\right]$} & 2 & 7 & 18 & 11 & 0.5841 \\
\hline 4 & {$\left[\begin{array}{lllll}0.3186 & 0.1052 & 0.3032 & 0.7009 \\
0.2002 & 0.3963 & 0.4131 & 0.6801\end{array}\right]$} & 7 & 1 & 11 & 19 & 1.0141 \\
\hline 5 & {$\left[\begin{array}{llll}0.5170 & 0.2002 & 0.5129 & 0.7579 \\
0.2688 & 0.3009 & 0.4985 & 0.8159\end{array}\right]$} & 6 & 10 & 12 & 10 & 0.4998 \\
\hline
\end{tabular}

TABLE VIII. HASIL PENGELOMPOKAN INDIKATOR PENDIDIKAN

\begin{tabular}{|c|c|c|}
\hline No. & Kabupaten / Kota & Kelompolk \\
\hline 1 & Pacitan & SEDANG \\
\hline 2 & Ponorogo & TINGGI \\
\hline 3 & Trenggalek & SEDANG \\
\hline 4 & Tulungagung & TINGGI \\
\hline 5 & Blitar & SEDANG \\
\hline 6 & Kediri & SEDANG \\
\hline 7 & Malang & SEDANG \\
\hline 8 & Lumajang & SEDANG \\
\hline 9 & Jember & SEDANG \\
\hline 10 & Banyuwangi & SEDANG \\
\hline 11 & Bondowoso & TINGGI \\
\hline 12 & Situbondo & TINGGI \\
\hline 13 & Probolinggo & SEDANG \\
\hline 14 & Pasuruan & SEDANG \\
\hline 15 & Sidoarjo & SANGAT TINGGI \\
\hline 16 & Mojolkerto & SEDANG \\
\hline 17 & Jombang & TINGGI \\
\hline 18 & Nganjuk & TINGGI \\
\hline 19 & Madiun & TINGGI \\
\hline 20 & Magetan & TINGGI \\
\hline 21 & Ngawi & SEDANG \\
\hline 22 & Bojonegoro & SEDANG \\
\hline 23 & Tuban & SEDANG \\
\hline 24 & Lamongan & TINGGI \\
\hline 25 & Gresik & TINGGI \\
\hline 26 & Bangkalan & RENDAH \\
\hline 27 & Sampang & RENDAH \\
\hline 28 & Pamekasan & TINGGI \\
\hline 29 & Sumenep & SEDANG \\
\hline 30 & Kota Kediri & SANGAT TINGGI \\
\hline 31 & Kota Blitar & SANGAT TINGGI \\
\hline 32 & Kota Malang & SANGAT TINGGI \\
\hline 33 & Kota Probolinggo & TINGGI \\
\hline 34 & Kota Pasuruan & SANGAT TINGGI \\
\hline 35 & Kota Mojokerto & SANGAT TINGGI \\
\hline 36 & Kota Madium & S.ANGAT TINGGI \\
\hline 37 & Kota Surabaya & SANGAT TINGGI \\
\hline 38 & Kota Batu & TINGGI \\
\hline
\end{tabular}

Berdasarkan hasil evaluasi tersebut maka kelompok yang terbentuk adalah hasil dari percobaan kedua karena mempunyai nilai DBI paling rendah. Kelompok kabupaten atau kota untuk indikator pendidikan dapat dilihat pada tabel 6 diatas.

\section{3) Indikator Standar Hidup Layak}

Pada indikator standar hidup layak, jumlah kelompok untuk setiap percobaan adalah 4 dan bobot yang digunakan untuk setiap percobaan ini adalah sebagai berikut.

$$
w=\left[\begin{array}{llll}
0,2 & 0,4 & 0,2 & 0,1 \\
0,2 & 0,1 & 0,3 & 0,5
\end{array}\right]
$$

Hasil Evaluasi dari percobaan pertama sampai kelima dapat dilihat pada tabel 7 .

TABLE IX. Evaluasi Pengujian Indikator Standar HiduP LAYAK 


\begin{tabular}{|c|ccc|c|c|c|c|c|}
\hline $\begin{array}{c}\text { Percobaan } \\
\text { ke - }\end{array}$ & Bobot akhir & $\begin{array}{c}\text { Clst. } \\
\mathbf{1}\end{array}$ & $\begin{array}{c}\text { Clst. } \\
\mathbf{2}\end{array}$ & $\begin{array}{c}\text { Clst. } \\
\mathbf{3}\end{array}$ & $\begin{array}{c}\text { Clst. } \\
\mathbf{4}\end{array}$ & DBI \\
\hline 1 & {$\left[\begin{array}{llll}0.1828 & 0.3105 & 0.4778 & 0.9241 \\
0.4183 & 0.0826 & 0.7808 & 0.8573\end{array}\right]$} & 21 & 4 & 10 & 3 & 0.2649 \\
\hline 2 & {$\left[\begin{array}{llll}0.4787 & 0.3060 & 0.1898 & 0.9606 \\
0.7811 & 0.0872 & 0.4123 & 0.8628\end{array}\right]$} & 10 & 4 & 21 & 3 & 0.2662 \\
\hline 3 & {$\left[\begin{array}{llll}0.1913 & 0.3378 & 0.1594 & 0.6396 \\
0.2679 & 0.0735 & 0.4932 & 0.7974\end{array}\right]$} & 11 & 3 & 12 & 12 & 0.6654 \\
\hline 4 & {$\left[\begin{array}{llll}0.1816 & 0.3971 & 0.2050 & 0.5525 \\
0.1844 & 0.1037 & 0.3985 & 0.7615\end{array}\right]$} & 5 & 2 & 18 & 13 & 0.6971 \\
\hline 5 & {$\left[\begin{array}{llll}0.1478 & 0.3648 & 0.2255 & 0.6245 \\
0.3028 & 0.1254 & 0.5071 & 0.7978\end{array}\right]$} & 11 & 4 & 11 & 12 & 0.6151 \\
\hline
\end{tabular}

Berdasarkan hasil evaluasi tersebut maka kelompok yang terbentuk adalah hasil dari percobaan pertama karena mempunyai nilai DBI paling rendah. Kelompok kabupaten atau kota untuk indikator standar hidup layak dapat dilihat pada table 8 .

Hasil yang didapat pada skenario pertama untuk pengujian tingkat akurasi sistem yakni sistem mempunyai akurasi tertinggi pada percobaan ketiga dengan nilai akurasi $84,21 \%$ dengan nilai laju pembelajaran 0,3 , fungsi pembelajaran 0,2, dan jumlah iterasi sebanyak 7 sedangkan nilai akurasi terendah ada pada percobaan pertama dengan nilai akurasi $60,52 \%$ dengan nilai laju pembelajaran 0,5 , fungsi pembelejaran 0,6 , dan jumlah iterasi sebanyak 5 .

Skenario pengujian kedua pada indikator kesehatan didapatkan hasil terbaik pada percobaan kedua dengan nilai DBI 0,2984 dengan nilai laju pembelajaran 0,6, fungsi pembelajaran 0,5 , dan jumlah iterasi sebanyak 6 . Nilai DBI terbesar didapatkan pada percobaan ketiga yakni 0,9539 dengan laju pembelajaran 0,3 , fungsi pembelajaran 0,2 , dan jumlah iterasi sebanyak 7 .

Skenario pengujian kedua pada indikator pendidikan didapatkan hasil terbaik pada percobaan kedua dengan nilai DBI 0,3098 dengan nilai laju pembelajaran 0,6, fungsi pembelajaran 0,5 , dan jumlah iterasi sebanyak 6 . Nilai DBI terbesar didapatkan pada percobaan keempat yakni 1,0141 dengan laju pembelajaran 0,1 , fungsi pembelajaran 0,4 , dan jumlah iterasi sebanyak 7 .

TABLE X. HASIl PENGELOMPOKAn IndiKator Standar Hidup LAYAK

\begin{tabular}{|c|c|c|}
\hline No. & Kabupaten / Kota & Kelompolk \\
\hline 1 & Pacitan & SEDANG \\
\hline 2 & Ponorogo & SEDANG \\
\hline 3 & Trenggalek & SEDANG \\
\hline 4 & Tulungagung & SEDANG \\
\hline 5 & Blitar & TINGGI \\
\hline 6 & Kediri & SEDANG \\
\hline 7 & Malang & SEDANG \\
\hline 8 & Lumajang & SEDANG \\
\hline 9 & Jember & SEDANG \\
\hline 10 & Banyuwangi & SEDANG \\
\hline 11 & Bondowroso & RENDAH \\
\hline 12 & Situbondo & SEDANG \\
\hline 13 & Probolinggo & SEDANG \\
\hline 14 & Pasuruan & SEDANG \\
\hline 15 & Sidoarjo & TINGGI \\
\hline 16 & Mojokerto & TINGGI \\
\hline 17 & Jombang & SEDANG \\
\hline 18 & Nganjuk & SEDANG \\
\hline 19 & Madiun & RENDAH \\
\hline 20 & Magetan & SEDANG \\
\hline 21 & Ngawi & RENDAH \\
\hline 22 & Bojonegoro & RENDAH \\
\hline 23 & Tuban & SEDANG \\
\hline 24 & Lamongan & SEDANG \\
\hline 25 & Gresik & TINGGI \\
\hline 26 & Bangkalan & SEDANG \\
\hline 27 & Sampang & SEDANG \\
\hline 28 & Pamekasan & SEDANG \\
\hline 29 & Sumenep & SEDANG \\
\hline 30 & Kota Kediri & TINGGI \\
\hline 31 & Kota Blitar & TINGGI \\
\hline 32 & Kota Malang & SANGAT TINGGI \\
\hline 33 & Kota Probolinggo & TINGGI \\
\hline 34 & Kota Pasuruan & TINGGI \\
\hline 35 & Kota Mojokerto & TINGGI \\
\hline 36 & Kota Madiun & SANGAT TINGGI \\
\hline 37 & Kota Surabaya & SANGAT TINGGI \\
\hline 38 & Kota Batu & TINGGI \\
\hline
\end{tabular}

Skenario pengujian kedua pada indikator standar hidup layak didapatkan hasil terbaik pada percobaan pertama dengan nilai DBI 0,2649 dengan nilai laju pembelajaran 0,5 , fungsi pembelajaran 0,6 , dan jumlah iterasi sebanyak 5. Nilai DBI terbesar didapatkan pada percobaan keempat yakni 0,6971 dengan laju pembelajaran 0,1 , fungsi pembelajaran 0,4, dan jumlah iterasi sebanyak 7 .

Setiap percobaan dengan parameter yang berbeda mempunyai nilai akurasi yang berbeda pula. Dari hasil percobaan pada pengujian sistem dapat disimpulkan bahwa parameter laju pembelajaran, fungsi pembelajaran, dan jumlah iterasi berpengaruh pada tingkat akurasi sistem.

\section{PENUTUP}

\section{A. Kesimpulan}

Berdasarkan hasil dari implementasi dan pengujian sistem, maka dalam penelitian tugas akhir ini dapat disimpulkan sebagai berikut:

1) Metode Self Oragnizing Maps (SOM) dapat mengelompokkan kabupaten atau kota di Jawa Timur berdasarkan indikator IPM yakni indikator kesehatan, indikator pendidikan, dan indikator standar hidup layak.

2) Pengelompokan kabupaten atau kota di Jawa Timur berdasarkan indikator IPM dapat membantu Bappeda Provinsi Jawa Timur untuk membantu 
menentukan kebijakan pembangunan kabupaten atau kota.

3) Nilai parameter yang digunakan pada metode SOM ini meliputi laju pembelajaran 0,6 , fungsi pembelajaran 0,5, dan jumlah iterasi 6 dalam pengujian tingkat akurasi pengelompokan kabupaten atau kota di Jawa Timur berdasarkan indikator IPM mempunyai nilai akurasi tertinggi yakni $84,21 \%$.

\section{B. Saran}

Adapun saran yang dapat diberikan oleh penulis untuk penelitian berikutnya apabila ingin mengembangkan sistem yang telah dibuat ini agar menjadi lebih baik adalah:

1) Pada penelitian ini, pemilihan nilai parameter SOM dalam pengujian masing-masing indikator masih menggunakan trial and error, yaitu melakukan beberapa kali percobaan untuk mendapatkan hasil yang terbaik. Disarankan untuk memilih nilai terbaik dengan mempertimbangkan nilai akurasi untuk setiap indikator.

2) Pada penelitian ini, masing-masing indikator IPM masih belum memiliki standar pengelompokan dari Bappeda sehingga metode yang digunakan adalah pembelajaran tidak terarah. Apabila dikemudian hari masing-masing indikator IPM mempunyai standar pengelompokan dari Bappeda maka disarankan untuk menggunakan metode lain.

\section{DAFTAR PUSTAKA}

[19] Badan Pusat Statistik. 2015. Indeks Pembangunan Manusia 2014 Metode Baru. Jakarta : BPS.

[20] BPS Provinsi Jawa Timur. 2015. Jawa Timur Dalam Angka 2014. Surabaya : BPS Provinsi Jawa Timur.

[21] Dinas Kesehatan Provinsi Jawa Timur. 2015. Profil Kesehatan Provinsi Jawa Timur 2014. Surabaya : Dinas Kesehatan Provinsi Jawa Timur.

[22] Prasetyo, Eko. 2013. Data Mining : Konsep dan Aplikasi Menggunakan Matlab. Jakarta : Andi Publisher.

[23] Edward. 2007. Clustering Menggunakan Self-Organizing Maps (Studi Kasus: Data PPMB IPB). Skripsi, FMIPA, Institut Pertanian Bogor, Bogor.

Santosa, Agung. 2013. Perancangan Sistem Pendukung Keputusan Pemetaan Profil Kecamatan Di Kabupaten Sragen Berdasarkan Indeks Pembangunan Manusia Menggunakan Algoritma Self Organizing Maps (SOM). Skripsi, Fakultas Teknik, Universitas Sebelas Maret, Surakarta. 